\title{
The Ocean's Elevator: Evolution of the air-seawater interface during a small-scale algal
}

\section{bloom}

Mickey M. Rogers ${ }^{\dagger}$, Jennifer F. Neal ${ }^{\dagger}$, Ankur Saha ${ }^{\dagger}$, Abdullah S. Algarni ${ }^{\dagger}$, Thomas C. J. Hill ", Heather C. Allen ${ }^{\dagger *}$

$\dagger$ Department of Chemistry \& Biochemistry, The Ohio State University, Columbus, OH 43210, United States

"Department of Atmospheric Science, Colorado State University, Fort Collins, Colorado 80523, United States

*Corresponding author E-mail: allen@chemistry.ohio-state.edu

KEYWORDS: Brewster angle microscopy, air-seawater gas exchange, algae, film thickness, sumfrequency generation spectroscopy, sea surface nanolayer, sea spray aerosols, marine algal bloom

\section{ABSTRACT}

The composition and lifetime of sea spray aerosols are driven by the molecular and biological complexity of the air-seawater interface. We explore in situ the surface properties of marine algal blooms of diatom monocultures by utilizing surface techniques of Brewster angle microscopy (BAM) imaging, vibrational sum frequency generation spectroscopy (SFG), and infrared reflection absorption spectroscopy (IRRAS). Over the course of the bloom, the marine algae produce surface-active biogenic molecules that temporally partition to the topmost interfacial layers and are selectively probed through surface imaging and spectroscopic measurements. BAM images show morphological structural changes and heterogeneity in the interfacial films with increasing density of surface-active biogenic molecules. Film thickness calculations quantified the average surface thickness over time. The image results reveal an $\sim 5 \mathrm{~nm}$ thick surface region in the late stages of the bloom which correlates to typical sea surface nanolayer thicknesses. These measurements serve to extract trends in air-seawater gas exchange dynamics, thus potentially 
aiding in climate modeling. Our surface-specific SFG spectroscopy results show significant diminishing in the intensity of the dangling $\mathrm{OH}$ bond of surface water molecules consistent with organic molecules partitioning and replacing water at the air-seawater interface as the algal bloom progresses. Interestingly, we observe a new broad peak appear between $3500 \mathrm{~cm}^{-1}$ to $3600 \mathrm{~cm}^{-1}$ in the late stages of the bloom that is attributed to weak hydrogen bonding interactions of water to the surface-active biogenic matter. IRRAS confirms the presence of organic molecules at the surface as we observe increasing intensity of vibrational alkyl modes and the appearance of a proteinaceous amide band. Our work shows the often overlooked but vast potential of tracking changes in the interfacial regime of small-scale laboratory marine algal blooms. By coupling surface imaging and vibrational spectroscopies to complex, time-evolving, marine-relevant systems, we provide additional insight into unraveling the temporal complexity of sea spray aerosol compositions.

\section{INTRODUCTION}

Biogenic enrichment at the air-seawater interface occurs throughout the course of a marine algal bloom. ${ }^{1-4}$ Marine algae produce proteins, lipids, and carbohydrates, among other surfaceactive organic molecules that partition to the air-seawater interface and contribute to the composition of the thin layer at the ocean's surface, known as the sea surface microlayer. ${ }^{5,6}$ The sea surface microlayer serves as the boundary between the ocean and atmosphere and is therefore crucial to the exchange of gases ${ }^{7,8}$ and a wide range of chemical and physical processes in the ocean and atmosphere. ${ }^{9}$ In addition to this, sea spray aerosols are introduced to the atmosphere through a wave-breaking mechanism at the ocean's surface including bubble entrainment and bursting. ${ }^{10,11}$ The changing biogeochemistry of algal systems throughout their bloom can alter the surface of the ocean, giving rise to dynamic sea spray aerosol composition. ${ }^{4,12,13}$ In this study, we 
investigate the marine-relevant diatom Skeletonema marinoi, ${ }^{14}$ known to produce surface-active organic molecules that include long-chain fatty acids. ${ }^{2}$ By tracking molecular and morphological changes at the air-seawater interface, we define the algal bloom as the "ocean's elevator" because it transfers biogenic material from bulk to surface, providing insight into the evolving surface properties throughout the bloom's lifetime.

Diatoms are the most abundant oceanic phytoplankton ${ }^{15}$ and exude an abundance of biogenic species over time, including proteins, lipids, and saccharides. ${ }^{2,16}$ The behavior of each subset of algal residues in ocean systems have been reported in the literature, exploring fundamental (one or two component) systems such as protein salt interactions, ${ }^{17-19}$ lipid monolayer surfaces (including fatty acids, fatty alcohols, phospholipids, among others), ${ }^{20,21}$ and saccharide enriched interfaces. ${ }^{3,22}$ By studying the individual role of each primary subset of algal exudates as demonstrated in the studies above, the fundamental interactions at the ocean's interface and consequent aerosol surfaces can be determined, and include interfacial adsorption ${ }^{17,22}$, binding interactions ${ }^{23,24}$, and reaction mechanisms ${ }^{25}$.

Biogenic surfactants have also been explored in more complex systems and have been shown to alter surface features ${ }^{26}$, enhance interactions ${ }^{19,20,27,28}$, and influence the overall film properties. ${ }^{29}$ Ex situ analysis of the interfacial regime of native marine systems has been reported, with some studies extending to surface tension measurements, ${ }^{26}$ Brewster angle microscopy (BAM), ${ }^{30,31}$ and sum frequency generation spectroscopy (SFG). ${ }^{6,32,33}$ Ex situ BAM imaging studies of highly productive sea surface samples show the heterogeneity due to a difference in packing density and the presence of gelatinous macroaggregates of natural films. ${ }^{30,34,35}$ Previous work by $\mathrm{La} \beta$ et al. using SFG spectroscopy to probe natural marine interfaces showed a significant decrease in the dangling $\mathrm{OH}$ of water molecules spanning the air-seawater interface, due to the presence of 
a film comprised of surface-active biogenic organics such as humic substances, carbohydrate-rich material, proteinaceous material, lipids, and hydrocarbons. ${ }^{36-38} \mathrm{La} \beta$ et al. suggested the presence of a 1-10 nm natural organic nanolayer, differing from the sea surface microlayer $(\sim 50 \mu \mathrm{m})^{6}$, comprised of a mixture of organics from marine samples. ${ }^{38}$ Furthermore, the biogenic enrichment of the sea surface nanolayer can control air-seawater gas exchange. ${ }^{33}$ Consistently, in this work we show that there is an $\sim 5 \mathrm{~nm}$ thick film produced over the course of the marine algal bloom.

We expand upon these studies by coupling imaging with vibrational spectroscopies in situ. BAM imaging, as well as surface-specific SFG spectroscopy and surface-sensitive infrared reflection-absorption spectroscopy (IRRAS) reveal interfacial structural changes of relevant biogenic processes during a marine algal bloom. The work presented here is conducted in situ to avoid disrupting these often-fragile systems. We track changes throughout the bloom and then calculate trends in film thickness, which aids in our understanding of air-seawater gas exchange behavior. Ultimately, we provide insights into the dynamic process occurring at the air-seawater interface and the role of algae as the ocean's elevator, which acts to transfer species between bulk seawater and the air-sea interface throughout its bloom. To our knowledge, this is the first BAM imaging and IRRAS study of a small-scale laboratory marine algal bloom in situ.

\section{EXPERIMENTAL}

\section{Materials}

Skeletonema marinoi, Sarno et Zingone (CCMP 2092), a marine diatom, was purchased as an axenic stock culture from the National Center for Marine Algae and Microbiota (NCMA) at Bigelow Laboratory, ME, USA. Filtered seawater (NCMA at Bigelow Laboratory) from the Gulf of Maine, ME, USA with 31-34 ppt salinity was triple bag-filtered through a $1 \mu \mathrm{m}$ pore size and 
autoclaved prior to use. Next, the seawater was enriched with nutrients $\left(\mathrm{NaNO}_{3}, \mathrm{NaH}_{2} \mathrm{PO}_{4} \bullet \mathrm{H}_{2} \mathrm{O}\right.$, $\mathrm{Na}_{2} \mathrm{SiO}_{3} \bullet 9 \mathrm{H}_{2} \mathrm{O}$, L1 trace element solution, and $\mathrm{f} / 2$ vitamin solution ${ }^{39,40}$ in a 1:1000 mL addition in $1 \mathrm{~L}$ Fisherbrand media bottles.

\section{Algae cultivation for Brewster angle microscopy}

S. marinoi was cultivated in a Teflon Langmuir trough (KSV NIMA, Biolin Scientific, Espoo, Finland, area $148.78 \mathrm{~cm}^{2}$ ) for Brewster angle microscopy. Prior to inoculation, the trough was thoroughly cleaned with reagent alcohol (Histological Grade, Fisher Scientific, Fair Lawn, NJ, USA) and ultrapure water with a resistivity of $18.2 \mathrm{M} \Omega \cdot \mathrm{cm}$ (Milli-Q Advantage A10, EMD Millipore, Billerica, MA, USA). The cleaned trough was filled with nutrient-enriched autoclaved and filtered seawater, inoculated with $1 \mathrm{~mL}$ of $S$. marinoi culture and exposed to a 13:11 hour day:night cycle (using BlueMax 70 Watt, Full Spectrum Solutions, MI, USA, 2,460 lumens). A water circulator (ISOTEMP 4100C, Fisher Scientific, Inc., PA, USA) was used to control the temperature of the solution in the trough at a constant temperature of $18^{\circ} \mathrm{C}$. The setup was housed in a black plexiglass box to prevent exposure to dust and other particulate matter. A small top-up of seawater was added to the trough daily to maintain volume, measured with BAM imaging.

\section{Algae cultivation for sum frequency generation and infrared reflection-absorption spectroscopy}

S. marinoi was cultivated in 9 Erlenmeyer wide-mouth flasks (Pyrex, $250 \mathrm{~mL}$ ) filled with $100 \mathrm{~mL}$ of nutrient-enriched autoclaved and filtered seawater, inoculated with $1 \mathrm{~mL}$ of $S$. marinoi algal culture, and capped with autoclaved cheesecloth plugs. The algae flasks were exposed to the same artificial light cycle as described above in a black plexiglass box. One flask was sampled for sum frequency generation and infrared reflection-absorption spectroscopy measurements by 
pipetting aliquots into a thoroughly cleaned borosilicate glass Petri dish and a Teflon Langmuir trough (KSV NIMA, Biolin Scientific, Espoo, Finland, area $144.5 \mathrm{~cm}^{2}$ ) with Delrin barriers (KSV NIMA). For comparison, spectra were obtained immediately after the 5-minute acquisition and after a 15-minute wait followed by 5-minute acquisition to allow for reestablishment of the sea surface layer. ${ }^{41,42}$ Once the flask was sampled, it was disposed of to avoid possible contamination in future sampling procedures. The flasks were housed in a black plexiglass box to prevent exposure to dust and other particulate matter.

\section{Methods}

\section{Brewster angle microscopy}

BAM imaging was performed using a custom-built BAM microscope. ${ }^{43,44}$ The BAM microscope is mounted on a goniometer to adjust the angle of incidence to the Brewster angle of an aqueous solution $\left(\sim 53^{\circ}\right.$ from the surface normal for pure water). The $1.5 \mathrm{~mW} \mathrm{He}-\mathrm{Ne}$ continuous wave laser source (Research Electro-Optics, Boulder, CO) emits polarized light at $543 \mathrm{~nm}$ which goes through a Glan polarizer, leaving purified p-polarized light to hit and reflect off the aqueous surface ${ }^{43}$ The reflected beam goes through a 10x infinity-corrected super-long working distance objective lens (CFI60 TU Plan EPI, Nikon Instruments, Melville, NY) and a tube lens (MXA22018, Nikon Instruments; focal length $200 \mathrm{~mm}$ ) to collect and collimate the beam before going into a back-illuminated EM-CCD camera (iXon DV887-BV, Andor Technology USA, Concord, MA; $512 \times 512$ active pixels with $16 \mu \mathrm{m} \times 16 \mu \mathrm{m}$ pixel size). The BAM images were processed using ImageJ software and cropped from their original size to show the region of highest resolution. An artificial blue color scale, with grey level values ranging from 1-100, was chosen to enhance image contrast. The light and dark blue of the images corresponds to regions with high and low coverage of surface-active species, respectively. 


\section{Sum frequency generation spectroscopy}

SFG spectroscopic measurements were obtained using a previously reported setup with minor modifications. ${ }^{23,45,46}$ In brief, the output beam from a regenerative Ti:sapphire amplifier (Spitfire Ace, Spectra-Physics) with a sub-50 fs $800 \mathrm{~nm}$ pulse is split where one-half is directed to an optical parametric amplifier (TOPAS-C, Light Conversion) coupled to a noncollinear difference frequency generator (NDFG, Light Conversion) to produce a tunable IR beam, and the other half of the visible beam is spectrally narrowed by an etalon (SLS Optics, United Kingdom). The IR and visible beams are incident onto the sample surface in a copropagating geometry at angles $60^{\circ}$ and $50^{\circ}$, respectively from the surface normal. The SF signal is collected in the reflected direction by a spectrometer (IsoPlane SCT 320, Princeton Instruments) and a liquid nitrogen cooled CCD $($ PyLoN, $1340 \times 400$ pixels, Princeton Instruments). Typical exposure time for one spectrum was 5 minutes. The spectra were collected in the polarization combination ssp which describes the polarization of the SF, visible, and IR beams respectively.

\section{Infrared reflection-absorption spectroscopy}

IRRAS spectra were recorded on an FT-IR spectrometer (Frontier, Perkin Elmer, United States) equipped with a liquid nitrogen cooled $\mathrm{HgCdTe}$ (MCT) detector previously described. ${ }^{47,48}$ Sampling was measured with two aligned gold-plated mirrors $(50.8 \mathrm{~mm})$ at an incident angle of $48^{\circ}$ from the surface normal. Spectra were recorded as an average of 400 scans in single beam mode. Spectra were collected under $s$-polarized light using a polarizer (Thorlabs, ZnSe Holographic Wire Grid Polarizer). Spectra were collected under compressed conditions (from $144.5 \mathrm{~cm}^{2}$ to $77.3 \mathrm{~cm}^{2}$ ) to concentrate the surface area. Data analysis was processed using Origin software. A $3^{\text {rd }}$ order polynomial background subtraction was used to fit the data. With the current geometry at an incidence angle of $48^{\circ}$, the peaks are observed as negative bands. 


\section{RESULTS AND DISCUSSION}

\section{Bloom progression and film thickness by temporal surface imaging}

To temporally assess algal bloom progression and the surface partitioning of organic molecules being produced by the bloom, we employed Brewster angle microscopy imaging. Figure 1a,b,c shows a schematic of the instrument optics, a picture of the bloom growing in the imaging set up (Teflon trough), and a diagram explaining Brewster's law, respectively. Reflectivity arises from changes in refractive index from the Brewster angle of the initial solution (i.e. the ocean water) to that of the biogenic film dominating the surface in the late stages of the bloom. The images in Figures 1d and S1a,b, the Supporting Information (SI), show independently grown algal blooms (time in days stated in the top left corner of each image). The dark areas (black and dark blue) of the images correspond to water-rich regions where there is a paucity of surface-active molecular species. Surface-active algal exudates partition to the air-seawater interface and correspond to the brighter areas (light blue and white) in the image. Our images show that the surface-active biogenic species begin to densely pack at the air-seawater interface, with the onset around day 7. By day 15 of the algal bloom, the images show an intense bright spot that indicates a possible multi-layer of surface-active species, similar to collapse structures of fatty acid films. ${ }^{21,49,50}$ Figure 1e shows the average grey level of the images over time, demonstrating the utility of using increasing grey level as a way to track the progress of the bloom. 
(a)

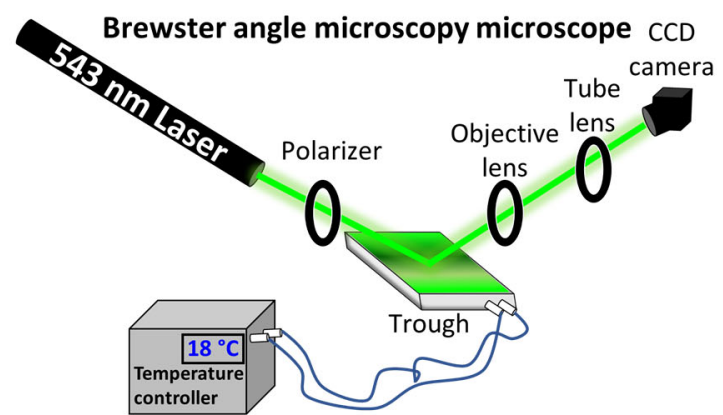

(d)

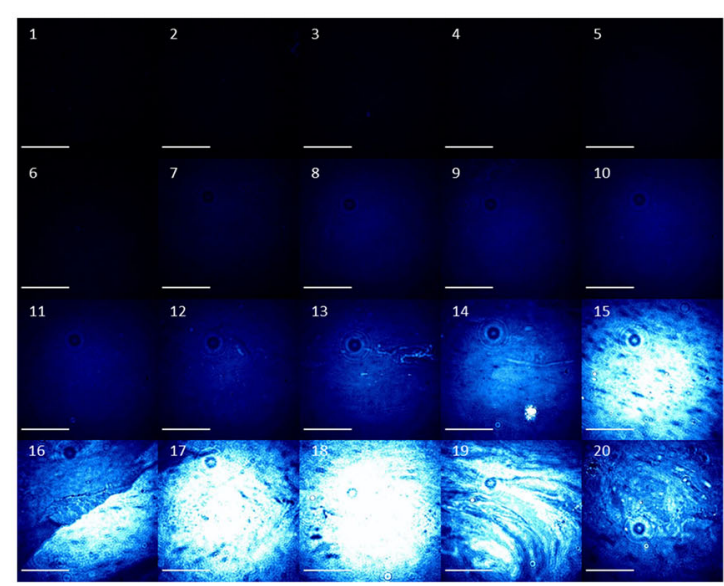

(b) Imaging setup

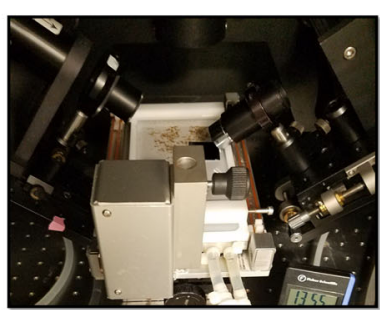

(c) Brewster's law

No Reflection Reflection

$\mathrm{n}_{\mathrm{a}}$
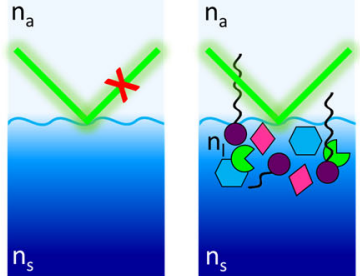

(e)

Grey levels

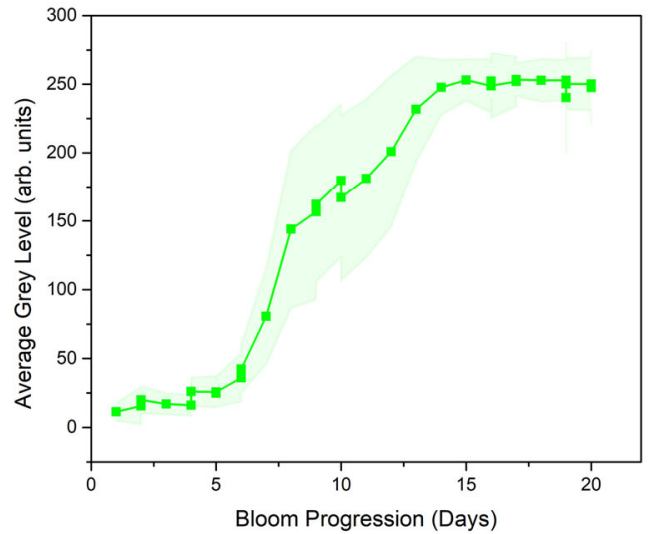

Figure 1. (a) Brewster angle microscope schematic showing the optics diagram, (b) imaging setup, (c) representation of Brewster's law showing no reflection off ocean water at the Brewster angle and light reflecting off the organic coated surface after the algae has grown, (d) surface images of the marine algal bloom at days 1-20 (day at the top left and 50 $\mu \mathrm{m}$ scale bar at bottom left), and (e) average grey level value over time.

To further understand the algal bloom, we calculated the relative film thickness using the BAM image data in a temporal window during late stages of the algal bloom (days 7-20). Assuming a relatively constant refractive index, the relative film thickness $(d)$ can be determined from the following relationship: ${ }^{51}$

$$
d=\frac{\lambda \sqrt{R_{p}}}{\pi \sin \left(2 \theta_{B}-90\right)} \frac{n_{l}^{2}\left(n_{a}^{2}-n_{S}^{2}\right)}{\sqrt{n_{a}^{2}+n_{s}^{2}}\left(n_{a}^{2}-n_{l}^{2}\right)\left(n_{s}^{2}-n_{l}^{2}\right)}
$$


where $\lambda$ is the laser wavelength, $R_{p}$ is the $p$-polarized reflectance, $n_{l}$ is the refractive index of the marine lipids, and $\theta_{\mathrm{B}}$ is the Brewster angle. The refractive indices of air and seawater were parameterized by $n_{a}=1.00$ and $n_{s}=1.35$, respectively. ${ }^{52}$ Lower and upper refractive index limits of representative relevant marine algal exudates such as saturated long-chain fatty acids $\left(\mathrm{n}_{1}=\right.$ $1.430)^{53,54}$ and phospholipids $(\mathrm{n}=1.478)^{55}$ were used to model film thickness, respectively. With diatoms being the most abundant oceanic phytoplankton ${ }^{15}$, and known for their abundance of lipids and phospholipids, our representative refractive indices are highly relevant. ${ }^{16,56,57}$ Moreover, studies show that in strains of Skeletonema, in particular, the primary fatty acid is palmitic acid (C16:0). ${ }^{2}$ Thus, we selected a saturated long-chain fatty acid's refractive index to model film thickness. Figure 2 shows the temporal evolution of the film thickness throughout the late stages of the bloom. The increase in film thickness suggests the release of surface-active organic molecules by productive algae. As the air-seawater interface becomes enriched with biogenic species and begins forming a film, the refractive index at the surface no longer resembles that of the solution, but rather the biogenic constituents of the surface film multi-layer.

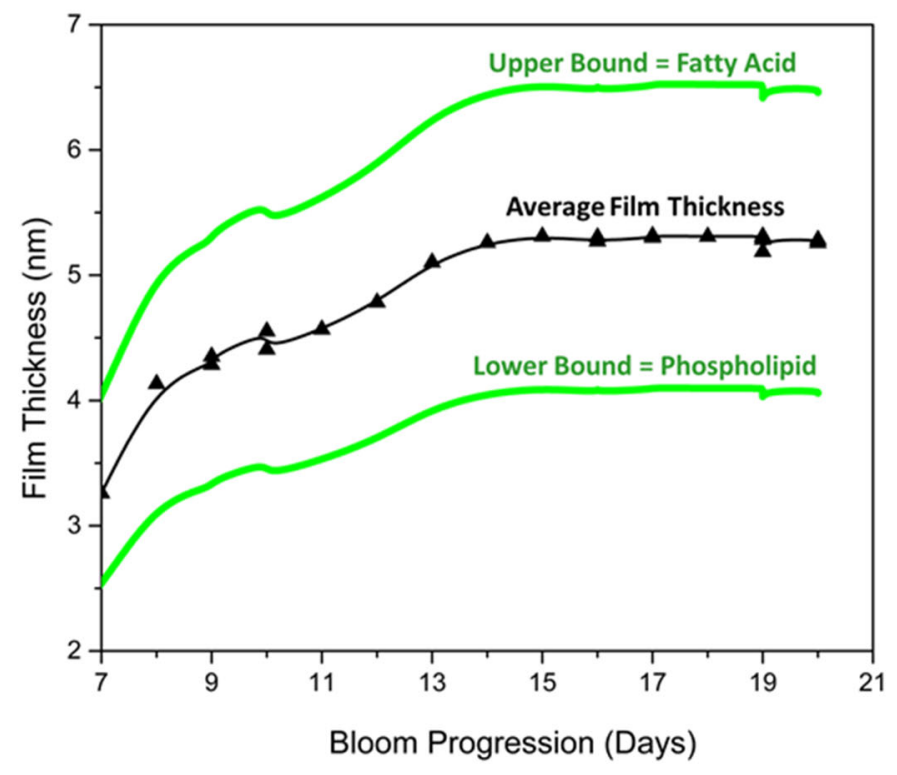


Figure 2. Film thickness (nm) of the late stage algal bloom versus time (days). The lower and upper bounds are defined by thickness calculations with representative refractive indices $\left(\mathrm{n}_{1}\right)$ where the lower limit is $n_{1}=1.430$ (saturated long-chain fatty acid) ${ }^{53,54}$ and the upper limit is $n_{1}=1.478$ (phospholipid). ${ }^{55}$

The late stages of the algal bloom reveal an average film thickness of $\sim 5 \mathrm{~nm}$. While monolayer thickness studies of relevant saturated long-chain fatty acids and phospholipids report average thicknesses ranging from $\sim 1.6-3 \mathrm{~nm}$, depending on the chemical composition of the subphase, our calculated thickness exceeds the monolayer regime suggesting the presence of a multi-layer film. ${ }^{45,55,58}$ Studies have demonstrated that the sea surface microlayer thickness varies depending on oceanic productivity and sampling technique, but averages $\sim 50 \mu \mathrm{m}$. ${ }^{1,6}$ There are also studies that suggest the sea surface microlayer is comprised of a nanolayer with thicknesses ranging from 2-30 nm, which is consistent with our findings. ${ }^{36,59}$ We deduce that as the algal bloom progresses, a multi-layer film forms yielding increased thickness concurrent with productivity. Furthermore, the heterogeneity of the late stage bloom images, as depicted in Figure 1d, correlates to gas transport processes in which gases escape more easily through weakened regions in the film. The morphological variety of these algal blooms is extraordinarily rich. More research is needed to fully grasp the variability and its implications for surface gas transport ${ }^{60,61}$.

\section{Interfacial water structure changes during a marine algal bloom}

Additional temporal insights into the air-seawater interface and the changing molecular environment of the interface resulting from the progression of an algal bloom can be determined with surface-specific sum frequency generation (SFG) spectroscopy. SFG spectroscopy is a nonlinear vibrational technique that selectively probes the non-centrosymmetric environment of an interface, such as that studied here - the air-seawater interface. It allows us to track changes in the interfacial hydration environment of a marine algal bloom progressing over time (i.e. at the 
minute and day timescales). As there is a break in symmetry at the air-seawater interface, we selectively probe the water molecules residing in this interfacial region and find that we water molecules are highly sensitive to reorganization of the biogenically produced molecules within the interface, thus providing a window into the algal bloom surface properties.

Figure 3a,b shows our surface-specific spectroscopic results in the vibrational region of water between $3750 \mathrm{~cm}^{-1}$ to $3100 \mathrm{~cm}^{-1}$ in the $s s p$ polarization combination $(s$-SFG, $s$-visible, $p$ infrared). Samples were collected after waiting 20 minutes (for more detail see Experimental Section, Algae cultivation for sum frequency generation and infrared reflection-absorption spectroscopy). The waiting period allows for the adsorption of molecules and reestablishment of the seawater's surface as described in SI, Figure S2. The spectrum for day 1 algae was taken multiple times for different bloom cycles to account for bloom onset variation (SI, Figure S3). As seen in Figure 3a, a peak at $3700 \mathrm{~cm}^{-1}$ is observed and is attributed to the dangling $\mathrm{OH}$ of water molecules pointing up into the air. ${ }^{24,62}$ Prior work has established that at the clean water surface, approximately 1 out of 4 water molecules contributes to the dangling $\mathrm{OH}$ population. ${ }^{63}$ The broad bands contribution to the region between $3100 \mathrm{~cm}^{-1}$ and $3600 \mathrm{~cm}^{-1}$ correspond to the hydrogen bonding network of interfacial water, specifically the $\mathrm{OH}$ stretching motions of surface water. The band centered at $\sim 3200 \mathrm{~cm}^{-1}$ is attributed to collective symmetric $\mathrm{OH}$ stretch motion in a strongly hydrogen bonded network; the band centered at $\sim 3450 \mathrm{~cm}^{-1}$ is attributed to the $\mathrm{OH}$ stretch of water in a more weakly hydrogen bonded environment. ${ }^{64-68}$ There are no significant spectral intensity or frequency differences when comparing the spectra for pure water, ocean water, and algae at day 1 spectra (Figure 3a). There is, however, a small diminishing of the dangling $\mathrm{OH}$ peak of water for algae on day 1 as compared to the other spectra. Overall, we observe relatively small deviations for the ocean water and the day 1 algae spectra, indicating that the algae are not producing 
sufficient surface-active biogenic molecules at this stage to alter the surface water organization, and the chains of algal cells are not surface active.

The spectra and schematic depiction of the algae at early and late stages of the bloom in Figure 3b,c show a significant deviation relative to the day 1 spectrum in Figure 3a. We find an exciting new peak around $\sim 3500 \mathrm{~cm}^{-1}$ to $3600 \mathrm{~cm}^{-1}$ and a significant diminishing of the free dangling $\mathrm{OH}$ of surface water molecules (Figure $3 b$ ). We attribute this new peak ranging from $\sim 3500 \mathrm{~cm}^{-1}$ to $3600 \mathrm{~cm}^{-1}$ to weak hydrogen bonding of water molecules to surface-active biological organics, consistent with prior work on anti-freeze proteins at the surface of water ${ }^{18}$ and carboxylic acid headgroups of fatty acids. ${ }^{24,69}$ The reduction in the dangling $\mathrm{OH}$ is consistent with organic molecules dominating the surface. ${ }^{70-72}$ These results are observed across blooms (SI, Figure S3) and correlate with the BAM images (Figure 1d), which show partitioning of algal exudates dominating the air-seawater surface, causing the reduction in the dangling $\mathrm{OH}$. 

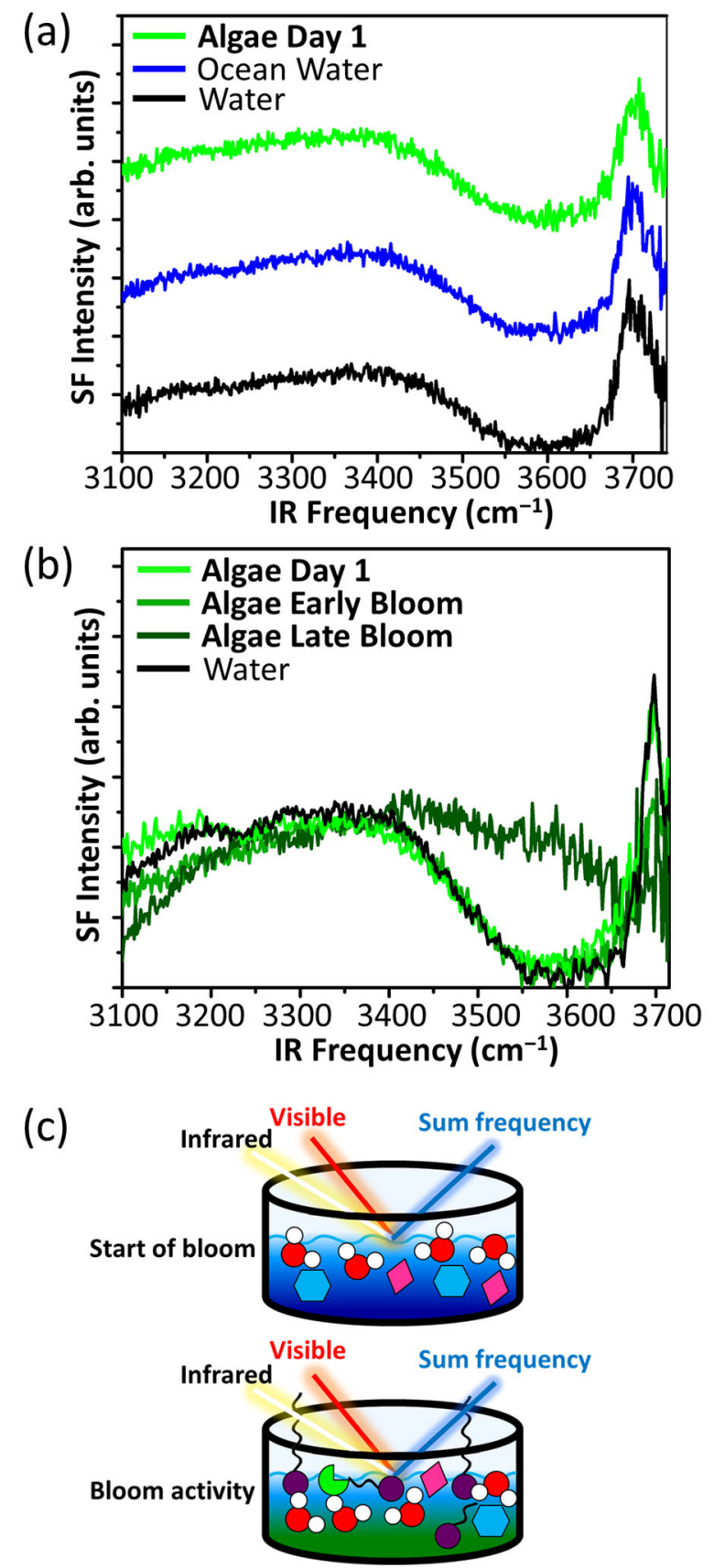

Figure 3. Sum frequency generation spectra in the water region from $3100 \mathrm{~cm}^{-1}$ to $3750 \mathrm{~cm}^{-1}$ of offset: (a) pure water (black), ocean water (blue), and algae at day 1 growth (light green), (b) algae at day 1 (light green), early bloom (green), late bloom (dark green), and pure water (black), and (c) a schematic representation of interfacial biogenic algal exudates throughout the bloom. 


\section{Organic partitioning to the aqueous surface using infrared reflection-absorption spectroscopy}

We further explore the interfacial organization at the molecular level during the course of the bloom using surface-sensitive infrared reflection absorption spectroscopy. IRRAS is a vibrational technique that provides complementary information to the SFG spectra of surface water. ${ }^{73,74}$ The benefit of the IRRAS technique is that a large spectral range is collected in a single acquisition from $4000-450 \mathrm{~cm}^{-1}$, and the mathematical ratioing in the IRRAS equation (Eqn. 2) provides surface-sensitive information. IRRAS spectra were plotted as reflectance-absorbance $(\mathrm{RA})^{47,48}$ which is given as:

$$
R A=-\log \left(R_{a l g} / R_{o}\right)
$$

where $\mathrm{R}_{\mathrm{alg}}$ is defined as the reflectivity of the algae and $\mathrm{R}_{\mathrm{o}}$ is the reflectivity of the seawater without algae.

Figure $4 \mathrm{a}, \mathrm{b}$ shows the spectra for early and late stages of the bloom, respectively, in the alkyl stretch region. The peaks, which are present at the late stages in the bloom and absent in early stages, at $\sim 2963 \mathrm{~cm}^{-1}, 2928 \mathrm{~cm}^{-1}$, and $\sim 2865 \mathrm{~cm}^{-1}$ correspond to the $\mathrm{CH}_{3}$-antisymmetric ( $\left.v_{\text {as }} \mathrm{CH}_{3}\right), \mathrm{CH}_{2}$-antisymmetric $\left(v_{\text {as }} \mathrm{CH}_{2}\right)$, and $\mathrm{CH}_{2}$-symmetric $\left(v_{\mathrm{s}} \mathrm{CH}_{2}\right)$ stretching modes, respectively. The presence of these alkyl modes in the late stages of the bloom confirms surfaceactive organic enrichment. ${ }^{47,75}$ Compared to a well-studied saturated long-chain fatty acid such as palmitic acid, we observe smaller peak intensity in the alkyl region and an $\sim 10 \mathrm{~cm}^{-1}$ blue shift for the $\mathrm{CH}_{2}$-antisymmetric stretching mode. ${ }^{25,76,77}$ The peak shift indicates there are more gauche conformers (more conformational disorder) of the alkyl chains in the algae spectrum compared to the organized fatty acid spectrum (SI, Figure S4). Moreover, we collect the IRRAS spectra with $s$ polarized light, which probes vibrations lateral to the surface, further supporting the presence of surface disorder caused by the gauche conformations. ${ }^{78}$ Our BAM imaging results, shown in 
Figure 1d, also agree and show the presence of a multi-layer film. The multi-layer film resembles more of a fatty acid, multi-layered, collapse structure, and not a single molecular layer, which would have more trans conformers.

The lower frequency region for both the early and late bloom stages are shown in Figure $4 \mathrm{c}, \mathrm{d}$. In the late stage of the bloom, the negative peak at $\sim 1451 \mathrm{~cm}^{-1}$ is assigned to the $\mathrm{CH}_{2}$ scissoring $\left(\delta \mathrm{CH}_{2}\right)$ and the negative band at $\sim 1534 \mathrm{~cm}^{-1}$ is assigned to the amide II region. The strong presence of the amide II band indicates the presence of protein. ${ }^{79-81}$ The amide II region is commonly present with the amide I peak, but is overlapping with our OH bend mode and not discernable. Current work is underway to utilize the low frequency IRRAS spectra for specific chemical identification.
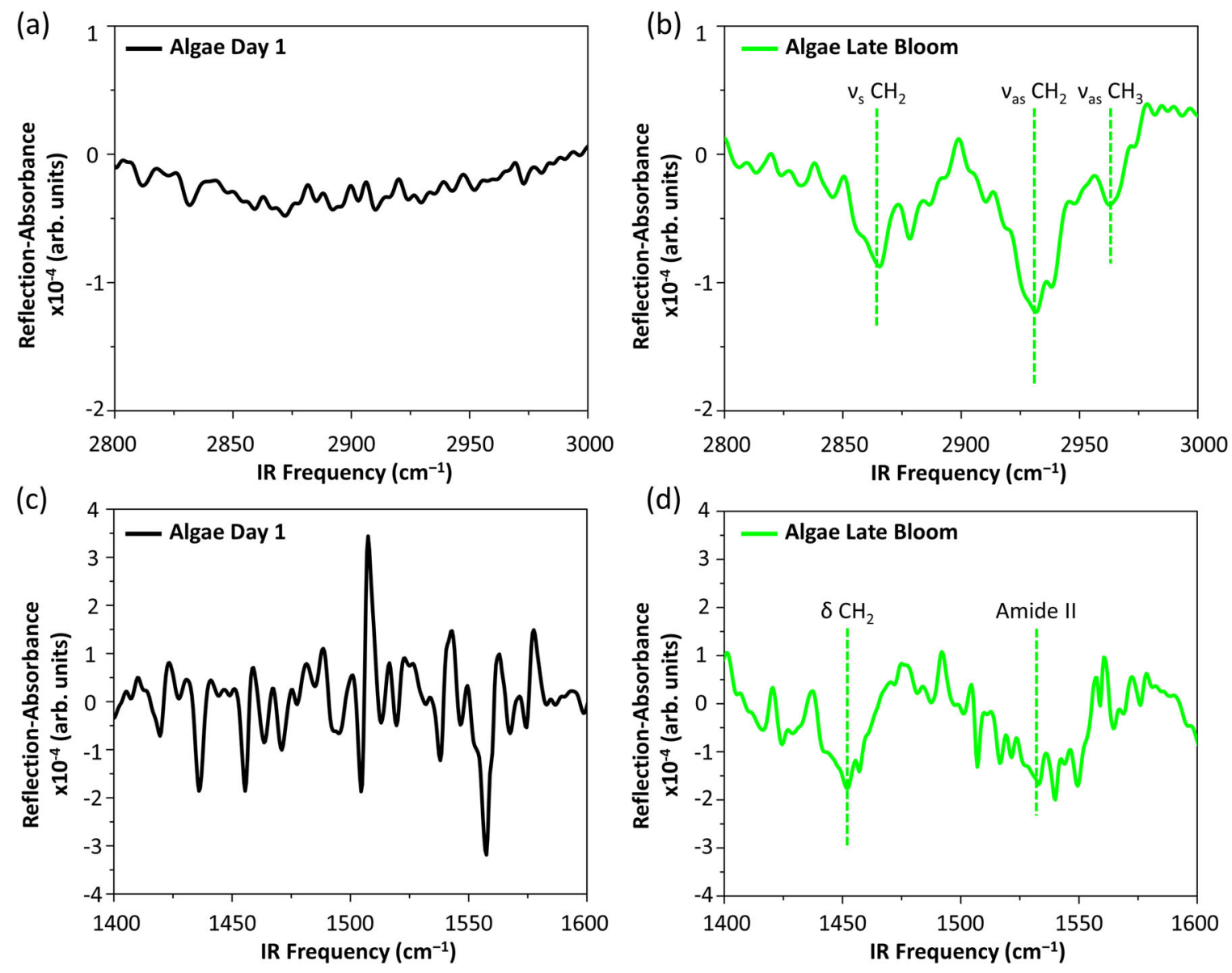
Figure 4. $s$-polarized IRRAS spectra, with peaks appearing as negative bands, of (a) day 1 in the alkyl region shows a lack of $\mathrm{C}-\mathrm{H}$ modes (black), (b) day 17 in the alkyl region with the presence of $\mathrm{C}-\mathrm{H}$ modes (lime green), (c) day 1 in the low frequency region (black) reveals only noise from incomplete subtraction of water vapor in the beam path, and (d) day 17 in the low frequency region shows the presence of the amide II broad band and C-H scissoring mode (lime green).

\section{Gas transport and atmospheric implications}

Assuming simple diffusion theory, ${ }^{82,83}$ the measured film thicknesses $(d)$ can be used to model trends in gas exchange by calculating the film permeability $\left(k_{m l}\right)$ by the simple relation: ${ }^{29}$

$$
k_{m l}=D_{m l} / d
$$

Where $D_{m l}$ is the diffusion coefficient of different atmospheric gases. By using a range of diffusion coefficients (SI, Figure S5), simple diffusion theory with in situ bloom measurements can be used to extract real trends in permeability. ${ }^{84}$ Representative diffusion coefficients ranging from $7 \times 10^{-5} \mathrm{~cm}^{2} \mathrm{~s}^{-1}$ to $1 \times 10^{-5} \mathrm{~cm}^{2} \mathrm{~s}^{-1}$ demonstrate the lower and upper bounds for several atmospheric gases in a range of ocean relevant temperatures. ${ }^{85-89}$ Seemingly, as the film becomes more concentrated throughout the bloom and the film thickness increases, the film permeability decreases. Interestingly, gases with larger diffusion coefficients show a more apparent exponential decrease in their permeability concurrent with film thickness, and are more greatly impeded by film thickness possibly due to the longer elapse of time required to permeate the film and the abrupt nature of physical aging resulting from the inherent kinetic nature of transitioning through the film. ${ }^{90,91}$

Serving as an important medium for air-seawater gas exchange and particle release via bubble bursting ${ }^{12}$, oceanic films have a critical role in impacting local marine environments, as well as global change ${ }^{5}$. Several climate models demonstrate the influence of phytoplankton 
dynamics on oceanic changes. ${ }^{92-94}$ Our study provides insights into how the native, undisturbed, in situ algal bloom behavior impacts air-seawater gas exchange and subsequent biogeochemical cycles.
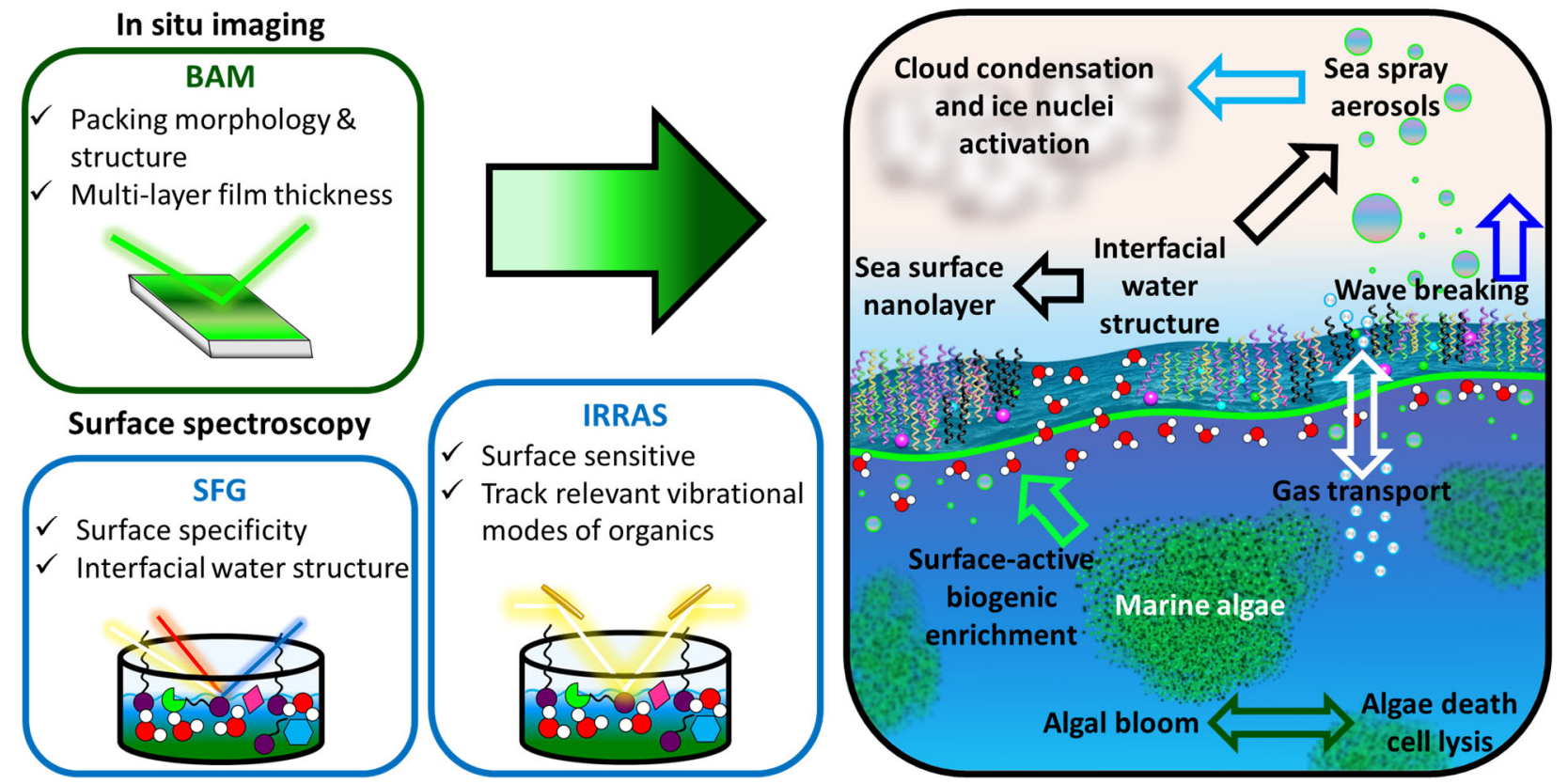

Figure 5. Schematic representation of how our surface techniques (BAM imaging, surface-specific SFG, and surface-sensitive IRRAS) advance understanding of oceanic interfacial evolution, gas transport, sea spray aerosols, among other processes.

As shown in Figure 5, we demonstrate the applicability of studying the ocean's elevator, marine algal blooms, by elucidating temporal molecular changes in film morphology, interfacial chemical composition, and global atmospheric processes. Temporal enhancement of surfaceactive algal exudates, observed by BAM imaging, surface-specific SFG and surface-sensitive IRRAS vibrational spectroscopies, correlate with the evolving chemical composition of the ocean surface, and that of sea spray aerosols (SSAs). We demonstrate the applicability of surface imaging and spectroscopic techniques as it provides an important role in the instrumental toolbox for interpreting oceanic and atmospheric changes. As depicted in Figure 5, breaking waves produce entrained air bubbles which surface to the air-seawater interface, the bubbles scavenge biogenic 
algal exudates, releasing enriched SSA upon bursting. ${ }^{10-12,95}$ Thus, following interfacial evolution at the air-seawater interface aids in understanding the sea surface micro- and nano-layer(s), gas transport processes, as well as the production and release of SSA, and their role in atmospheric cycles such as cloud and ice formation. ${ }^{96,97}$ Current work in our lab is underway to identify the chemical composition of the air-seawater interface using additional surface techniques to monitor small-scale laboratory marine algal bloom exudates.

\section{CONCLUSION}

We temporally tracked changes in the air-seawater interface of small-scale laboratory marine algal blooms using a suite of surface imaging and spectroscopic techniques. As the marine algal bloom progresses, Brewster angle microscopy imaging shows the enhancement of surfaceactive species dominating the interface and film thickness calculations reveal an increasing thickness for late bloom stages, averaging $\sim 5 \mathrm{~nm}$ thick. Sum frequency generation spectroscopy reveals significant diminishing in the intensity of the dangling $\mathrm{OH}$ of surface waters, which supports the partitioning of algal exudates to the air-seawater interface. Overtime, a new, broad peak manifests between $3500 \mathrm{~cm}^{-1}$ to $3600 \mathrm{~cm}^{-1}$, consistent with weak hydrogen bonding networks interacting with organic and biological species. Infrared reflection-absorption spectroscopy spectra also exhibit a temporal increase in the intensity of the alkyl stretch region and the proteinaceous amide band, in accord with natural marine algal bloom growth cycles. Assuming simple gas exchange relationships, this study extracts trends in film permeability which is important for climate modeling. Moreover, we begin to unravel the complex role of algae as the ocean's elevator which acts to transfer gases and particles between bulk seawater and the air-seawater interface. To the author's knowledge, this is the first temporal Brewster angle microscopy and infrared reflection-absorption spectroscopy study in situ of small-scale laboratory marine algal blooms. 


\section{ASSOCIATED CONTENT}

\section{Supporting Information}

The Supporting Information is available free of charge on the website at DOI:

\section{AUTHOR INFORMATION}

Corresponding author

*Email: allen@chemistry.ohio-state.edu. Phone: +1-614-292-4707. Fax: +1-614-292-1685.

Notes

The authors declare no competing financial interest.

\section{ACKNOWLEDGMENTS}

We acknowledge support by NSF through the Center for Aerosol Impacts on Chemistry of the Environment (CAICE), CHE-1801971. Data archiving is underway at the UC San Diego Library Digital Collections for CAICE website: https://library.ucsd.edu/dc/collection/bb96275693. The authors declare no competing financial interest. The authors would like to thank K. Carter-Fenk and B. Rogers for insightful comments on the manuscript. 


\section{REFERENCES}

(1) Engel, A.; Sperling, M.; Sun, C.; Grosse, J.; Friedrichs, G. Organic Matter in the Surface Microlayer: Insights from a Wind Wave Channel Experiment. Front. Mar. Sci. 2018, 5. https://doi.org/10.3389/fmars.2018.00182.

(2) Jónasdóttir, S. H. Fatty Acid Profiles and Production in Marine Phytoplankton. Mar. Drugs 2019, 17 (3), 151. https://doi.org/10.3390/md17030151.

(3) Jayarathne, T.; Sultana, C. M.; Lee, C.; Malfatti, F.; Cox, J. L.; Pendergraft, M. A.; Moore, K. A.; Azam, F.; Tivanski, A. V.; Cappa, C. D.; Bertram, T. H.; Grassian, V. H.; Prather, K. A.; Stone, E. A. Enrichment of Saccharides and Divalent Cations in Sea Spray Aerosol During Two Phytoplankton Blooms. Environ. Sci. Technol. 2016, 50 (21), 11511-11520. https://doi.org/10.1021/acs.est.6b02988.

(4) Wang, X.; Sultana, C. M.; Trueblood, J.; Hill, T. C. J.; Malfatti, F.; Lee, C.; Laskina, O.; Moore, K. A.; Beall, C. M.; McCluskey, C. S.; Cornwell, G. C.; Zhou, Y.; Cox, J. L.; Pendergraft, M. A.; Santander, M. V.; Bertram, T. H.; Cappa, C. D.; Azam, F.; DeMott, P. J.; Grassian, V. H.; Prather, K. A. Microbial Control of Sea Spray Aerosol Composition: A Tale of Two Blooms. ACS Cent. Sci. 2015, 1 (3), 124131. https://doi.org/10.1021/acscentsci.5b00148.

(5) Burrows, S. M.; Ogunro, O.; Frossard, A. A.; Russell, L. M.; Rasch, P. J.; Elliott, S. A Physically-Based Framework for Modelling the Organic Fractionation of Sea Spray Aerosol from Bubble Film Langmuir Equilibria. Atmos. Chem. Phys. Discuss. 2014, 14 (5), 5375-5443. https://doi.org/10.5194/acpd-14-5375-2014.

(6) Engel, A.; Galgani, L. The Organic Sea-Surface Microlayer in the Upwelling Region off the Coast of Peru and Potential Implications for Air-Sea Exchange Processes. Biogeosciences 2016, 13 (4), 9891007. https://doi.org/10.5194/bg-13-989-2016.

(7) Wurl, O.; Stolle, C.; Van Thuoc, C.; The Thu, P.; Mari, X. Biofilm-like Properties of the Sea Surface and Predicted Effects on Air-Sea CO2 Exchange. Prog. Oceanogr. 2016, 144, 15-24. https://doi.org/10.1016/j.pocean.2016.03.002.

(8) Mustaffa, N. I. H.; Ribas-Ribas, M.; Banko-Kubis, H. M.; Wurl, O. Global Reduction of in Situ CO2 Transfer Velocity by Natural Surfactants in the Sea-Surface Microlayer. P. Roy. Soc. A - Math Phy. 2020, 476 (2234), 20190763. https://doi.org/10.1098/rspa.2019.0763.

(9) Prather, K. A.; Bertram, T. H.; Grassian, V. H.; Deane, G. B.; Stokes, M. D.; DeMott, P. J.; Aluwihare, L. I.; Palenik, B. P.; Azam, F.; Seinfeld, J. H.; Moffet, R. C.; Molina, M. J.; Cappa, C. D.; Geiger, F. M.; Roberts, G. C.; Russell, L. M.; Ault, A. P.; Baltrusaitis, J.; Collins, D. B.; Corrigan, C. E.; CuadraRodriguez, L. A.; Ebben, C. J.; Forestieri, S. D.; Guasco, T. L.; Hersey, S. P.; Kim, M. J.; Lambert, W. F.; Modini, R. L.; Mui, W.; Pedler, B. E.; Ruppel, M. J.; Ryder, O. S.; Schoepp, N. G.; Sullivan, R. C.; Zhao, D. Bringing the Ocean into the Laboratory to Probe the Chemical Complexity of Sea Spray Aerosol. PNAS 2013, 110 (19), 7550-7555. https://doi.org/10.1073/pnas.1300262110.

(10) Blanchard, D. C. The Ejection of Drops from the Sea and Their Enrichment with Bacteria and Other Materials: A Review. Estuaries 1989, 12 (3), 127-137. https://doi.org/10.2307/1351816.

(11) Blanchard, D. C. The Electrification of the Atmosphere by Particles from Bubbles in the Sea. Prog. Oceanogr. 1963, 1, 73-202. https://doi.org/10.1016/0079-6611(63)90004-1.

(12) Wang, X.; Deane, G. B.; Moore, K. A.; Ryder, O. S.; Stokes, M. D.; Beall, C. M.; Collins, D. B.; Santander, M. V.; Burrows, S. M.; Sultana, C. M.; Prather, K. A. The Role of Jet and Film Drops in Controlling the Mixing State of Submicron Sea Spray Aerosol Particles. PNAS 2017, 114 (27), 69786983. https://doi.org/10.1073/pnas.1702420114.

(13) Lee, C.; Sultana, C. M.; Collins, D. B.; Santander, M. V.; Axson, J. L.; Malfatti, F.; Cornwell, G. C.; Grandquist, J. R.; Deane, G. B.; Stokes, M. D.; Azam, F.; Grassian, V. H.; Prather, K. A. Advancing 
Model Systems for Fundamental Laboratory Studies of Sea Spray Aerosol Using the Microbial Loop. J. Phys. Chem. A 2015, 119 (33), 8860-8870. https://doi.org/10.1021/acs.jpca.5b03488.

(14) Sarno, D.; Kooistra, W. H. C. F.; Medlin, L. K.; Percopo, I.; Zingone, A. Diversity in the Genus Skeletonema (Bacillariophyceae). Ii. an Assessment of the Taxonomy of S. Costatum-Like Species with the Description of Four New Species1. J. Phycol. 2005, 41 (1), 151-176. https://doi.org/10.1111/j.1529-8817.2005.04067.x.

(15) Zulu, N. N.; Zienkiewicz, K.; Vollheyde, K.; Feussner, I. Current Trends to Comprehend Lipid Metabolism in Diatoms. Prog. Lipid Res. 2018, 70, 1-16. https://doi.org/10.1016/j.plipres.2018.03.001.

(16) Vidoudez, C.; Pohnert, G. Comparative Metabolomics of the Diatom Skeletonema Marinoi in Different Growth Phases. Metabolomics 2012, 8 (4), 654-669. https://doi.org/10.1007/s11306011-0356-6.

(17) Li, Y.; Shrestha, M.; Luo, M.; Sit, I.; Song, M.; Grassian, V. H.; Xiong, W. Salting Up of Proteins at the Air/Water Interface. Langmuir 2019, 35 (43), 13815-13820. https://doi.org/10.1021/acs.langmuir.9b01901.

(18) Meister, K.; Strazdaite, S.; DeVries, A. L.; Lotze, S.; Olijve, L. L. C.; Voets, I. K.; Bakker, H. J. Observation of Ice-like Water Layers at an Aqueous Protein Surface. Proc. Natl. Acad. Sci. USA 2014, 111 (50), 17732-17736. https://doi.org/10.1073/pnas.1414188111.

(19) Luo, M.; Dommer, A. C.; Schiffer, J. M.; Rez, D. J.; Mitchell, A. R.; Amaro, R. E.; Grassian, V. H. Surfactant Charge Modulates Structure and Stability of Lipase-Embedded Monolayers at MarineRelevant Aerosol Surfaces. Langmuir 2019, 35 (27), 9050-9060. https://doi.org/10.1021/acs.langmuir.9b00689.

(20) Neal, J. F.; Rogers, M. M.; Smeltzer, M. A.; Carter-Fenk, K. A.; Grooms, A. J.; Zerkle, M. M.; Allen, H. C. Sodium Drives Interfacial Equilibria for Semi-Soluble Phosphoric and Phosphonic Acids of Model Sea Spray Aerosol Surfaces. ACS Earth Space Chem. 2020. https://doi.org/10.1021/acsearthspacechem.0c00132.

(21) Carter-Fenk, K. A.; Allen, H. C. Collapse Mechanisms of Nascent and Aged Sea Spray Aerosol Proxy Films. Atmosphere 2018, 9 (12), 503. https://doi.org/10.3390/atmos9120503.

(22) Hasenecz, E. S.; Kaluarachchi, C. P.; Lee, H. D.; Tivanski, A. V.; Stone, E. A. Saccharide Transfer to Sea Spray Aerosol Enhanced by Surface Activity, Calcium, and Protein Interactions. ACS Earth Space Chem. 2019, 3 (11), 2539-2548. https://doi.org/10.1021/acsearthspacechem.9b00197.

(23) Adams, E. M.; Wellen, B. A.; Thiraux, R.; Reddy, S. K.; Vidalis, A. S.; Paesani, F.; Allen, H. C. SodiumCarboxylate Contact Ion Pair Formation Induces Stabilization of Palmitic Acid Monolayers at High PH. Phys. Chem. Chem. Phys. 2017, 19 (16), 10481-10490. https://doi.org/10.1039/C7CP00167C.

(24) Hua, W.; Verreault, D.; Huang, Z.; Adams, E. M.; Allen, H. C. Cation Effects on Interfacial Water Organization of Aqueous Chloride Solutions. I. Monovalent Cations: $\mathrm{Li}^{+}, \mathrm{Na}^{+}, \mathrm{K}^{+}$, and $\mathrm{NH}^{+}$. J. Phys. Chem. B 2014, 118 (28), 8433-8440. https://doi.org/10.1021/jp503132m.

(25) Shrestha, M.; Luo, M.; Li, Y.; Xiang, B.; Xiong, W.; Grassian, V. H. Let There Be Light: Stability of Palmitic Acid Monolayers at the Air/Salt Water Interface in the Presence and Absence of Simulated Solar Light and a Photosensitizer. Chem. Sci. 2018, 9 (26), 5716-5723. https://doi.org/10.1039/C8SC01957F.

(26) Lee, H. D.; Morris, H. S.; Laskina, O.; Sultana, C. M.; Lee, C.; Jayarathne, T.; Cox, J. L.; Wang, X.; Hasenecz, E. S.; DeMott, P. J.; Bertram, T. H.; Cappa, C. D.; Stone, E. A.; Prather, K. A.; Grassian, V. H.; Tivanski, A. V. Organic Enrichment, Physical Phase State, and Surface Tension Depression of Nascent Core-Shell Sea Spray Aerosols during Two Phytoplankton Blooms. ACS Earth Space Chem. 2020, 4 (4), 650-660. https://doi.org/10.1021/acsearthspacechem.0c00032.

(27) Schiffer, J. M.; Luo, M.; Dommer, A. C.; Thoron, G.; Pendergraft, M.; Santander, M. V.; Lucero, D.; Pecora de Barros, E.; Prather, K. A.; Grassian, V. H.; Amaro, R. E. Impacts of Lipase Enzyme on the 
Surface Properties of Marine Aerosols. J. Phys. Chem. Lett. 2018, 9 (14), 3839-3849. https://doi.org/10.1021/acs.jpclett.8b01363.

(28) Burrows, S. M.; Gobrogge, E.; Fu, L.; Link, K.; Elliott, S. M.; Wang, H.; Walker, R. OCEANFILMS-2: Representing Coadsorption of Saccharides in Marine Films and Potential Impacts on Modeled Marine Aerosol Chemistry. Geophys. Res. Lett. 2016, 43 (15), 8306-8313. https://doi.org/10.1002/2016GL069070.

(29) Farajzadeh, R.; Krastev, R.; Zitha, P. L. J. Foam Film Permeability: Theory and Experiment. Adv. Colloid Interface Sci. 2008, 137 (1), 27-44. https://doi.org/10.1016/j.cis.2007.08.002.

(30) Kozarac, Z.; Risović, D.; Frka, S.; Möbius, D. Reflection of Light from the Air/Water Interface Covered with Sea-Surface Microlayers. Mar. Chem. 2005, 96 (1), 99-113. https://doi.org/10.1016/j.marchem.2004.12.003.

(31) Kozarac, Z.; Möbius, D.; Spohn, D. B. Investigation of Sea-Surface Microlayer and Phytoplankton Culture Samples by Monolayer Techniques and Brewster Angle Microscopy. Croatica Chemica Acta 1998, 71 (2), 285-301.

(32) Engel, A.; Bange, H. W.; Cunliffe, M.; Burrows, S. M.; Friedrichs, G.; Galgani, L.; Herrmann, H.; Hertkorn, N.; Johnson, M.; Liss, P. S.; Quinn, P. K.; Schartau, M.; Soloviev, A.; Stolle, C.; UpstillGoddard, R. C.; van Pinxteren, M.; Zäncker, B. The Ocean's Vital Skin: Toward an Integrated Understanding of the Sea Surface Microlayer. Front. Mar. Sci. 2017, 4. https://doi.org/10.3389/fmars.2017.00165.

(33) Engel, A.; Sperling, M.; Sun, C.; Grosse, J.; Friedrichs, G. Organic Matter in the Surface Microlayer: Insights From a Wind Wave Channel Experiment. Front. Mar. Sci. 2018, 5. https://doi.org/10.3389/fmars.2018.00182.

(34) Gašparović, B.; Kozarac, Z.; Saliot, A.; Ćosović, B.; Möbius, D. Physicochemical Characterization of Natural Andex-SituReconstructed Sea-Surface Microlayers. J. Colloid Interface Sci. 1998, 208 (1), 191-202. https://doi.org/10.1006/jcis.1998.5792.

(35) Kozarac, Z.; Möbius, D.; Romero, M. T. M. Characterization of Aquatic Natural Microlayers by Monolayer Techniques and Brewster Angle Microscopy. Water Res. 2000, 34 (5), 1463-1472. https://doi.org/10.1016/S0043-1354(99)00300-0.

(36) Laß, K.; Kleber, J.; Friedrichs, G. Vibrational Sum-Frequency Generation as a Probe for Composition, Chemical Reactivity, and Film Formation Dynamics of the Sea Surface Nanolayer. Limnol. Oceanogr. - Meth. 2010, 8 (5), 216-228. https://doi.org/10.4319/lom.2010.8.216.

(37) Laß, K.; Friedrichs, G. Revealing Structural Properties of the Marine Nanolayer from Vibrational Sum Frequency Generation Spectra. J. Geophys. Res. Oceans 2011, 116 (C8). https://doi.org/10.1029/2010JC006609.

(38) Laß, K.; Bange, H. W.; Friedrichs, G. Seasonal Signatures in SFG Vibrational Spectra of the Sea Surface Nanolayer at Boknis Eck Time Series Station (SW Baltic Sea). Biogeosciences 2013, 10 (8), 5325-5334. https://doi.org/10.5194/bg-10-5325-2013.

(39) Guillard, R. R. L. Culture of Phytoplankton for Feeding Marine Invertebrates. In Culture of Marine Invertebrate Animals: Proceedings - 1st Conference on Culture of Marine Invertebrate Animals Greenport; Smith, W. L., Chanley, M. H., Eds.; Springer US: Boston, MA, 1975; pp 29-60. https://doi.org/10.1007/978-1-4615-8714-9_3.

(40) Guillard, R. R. L.; Ryther, J. H. Studies of Marine Planktonic Diatoms: I. Cyclotella Nana Hustedt, and Detonula Confervacea (Cleve) Gran. Can. J. Microbiol. 1962, 8 (2), 229-239. https://doi.org/10.1139/m62-029.

(41) Frew, N. M. The Role of Organic Films in Air-Sea Gas Exchange. In The Sea Surface and Global Change; Liss, P. S., Duce, R. A., Eds.; Cambridge University Press: Cambridge, 1997; pp 121-172. https://doi.org/10.1017/CBO9780511525025.006. 
(42) Schmidt, R. Einfluss Natürlicher Organischer Filme Auf Den Gasaustausch Zwischen Meer Und Atmosphäre. diploma, Universität Rostock, 2009.

(43) Neal, J. F.; Zhao, W.; Grooms, A. J.; Flood, A. H.; Allen, H. C. Arginine-Phosphate Recognition Enhanced in Phospholipid Monolayers at Aqueous Interfaces. J. Phys. Chem. C 2018, 122 (46), 26362-26371. https://doi.org/10.1021/acs.jpcc.8b03531.

(44) Adams, E. M.; Allen, H. C. Palmitic Acid on Salt Subphases and in Mixed Monolayers of Cerebrosides: Application to Atmospheric Aerosol Chemistry. Atmosphere 2013, 4 (4), 315-336. https://doi.org/10.3390/atmos4040315.

(45) Adams, E. M.; Verreault, D.; Jayarathne, T.; Cochran, R. E.; Stone, E. A.; Allen, H. C. Surface Organization of a DPPC Monolayer on Concentrated $\mathrm{SrCl}_{2}$ and $\mathrm{ZnCl}_{2}$ Solutions. Phys. Chem. Chem. Phys. 2016, 18 (47), 32345-32357. https://doi.org/10.1039/C6CP06887A.

(46) Lin, L.; Husek, J.; Biswas, S.; Baumler, S. M.; Adel, T.; Ng, K. C.; Baker, L. R.; Allen, H. C. Iron(III) Speciation Observed at Aqueous and Glycerol Surfaces: Vibrational Sum Frequency and X-Ray. J. Am. Chem. Soc. 2019, 141 (34), 13525-13535. https://doi.org/10.1021/jacs.9b05231.

(47) Neal, J. F.; Zhao, W.; Grooms, A. J.; Smeltzer, M. A.; Shook, B. M.; Flood, A. H.; Allen, H. C. Interfacial Supramolecular Structures of Amphiphilic Receptors Drive Aqueous Phosphate Recognition. J. Am. Chem. Soc. 2019, 141 (19), 7876-7886. https://doi.org/10.1021/jacs.9b02148.

(48) Grooms, A. J.; Neal, J. F.; Ng, K. C.; Zhao, W.; Flood, A. H.; Allen, H. C. Thermodynamic Signatures of the Origin of Anti-Hofmeister Selectivity for Phosphate at Aqueous Interfaces. J. Phys. Chem. A 2020, 124 (27), 5621-5630. https://doi.org/10.1021/acs.jpca.0c02515.

(49) Lee, K. Y. C. Collapse Mechanisms of Langmuir Monolayers. Annu. Rev. Phys. Chem. 2008, 59 (1), 771-791. https://doi.org/10.1146/annurev.physchem.58.032806.104619.

(50) McFate, C.; Ward, D.; Olmsted, J. Organized Collapse of Fatty Acid Monolayers. Langmuir 1993, 9 (4), 1036-1039. https://doi.org/10.1021/la00028a026.

(51) Pusterla, J. M.; Malfatti-Gasperini, A. A.; Puentes-Martinez, X. E.; Cavalcanti, L. P.; Oliveira, R. G. Refractive Index and Thickness Determination in Langmuir Monolayers of Myelin Lipids. BBA Biomembranes 2017, 1859 (5), 924-930. https://doi.org/10.1016/j.bbamem.2017.02.005.

(52) Austin, R. W.; Halikas, G. The Index of Refraction of Seawater: Defense Technical Information Center: Fort Belvoir, VA, 1976. https://doi.org/10.21236/ADA024800.

(53) Ayoub, G. T.; Bashara, N. M. Characterization of a Very Thin Uniaxial Film on a Nonabsorbing Substrate by Multiple Wavelength Ellipsometry: Palmitic Acid on Water*. J. Opt. Soc. Am., JOSA 1978, 68 (7), 978-983. https://doi.org/10.1364/JOSA.68.000978.

(54) Craig, B. M. Refractive Indices of Some Saturated and Monoethenoid Fatty Acids and Methyl Esters. Can. J. Chem. 1953, 31 (5), 499-504. https://doi.org/10.1139/v53-068.

(55) Kienle, D. F.; de Souza, J. V.; Watkins, E. B.; Kuhl, T. L. Thickness and Refractive Index of DPPC and DPPE Monolayers by Multiple-Beam Interferometry. Anal. Bioanal. Chem. 2014, 406 (19), 47254733. https://doi.org/10.1007/s00216-014-7866-9.

(56) Obata, T.; Fernie, A. R.; Nunes-Nesi, A. The Central Carbon and Energy Metabolism of Marine Diatoms. Metabolites 2013, 3 (2), 325-346. https://doi.org/10.3390/metabo3020325.

(57) Geider, R.; Roche, J. L. Redfield Revisited: Variability of C:N:P in Marine Microalgae and Its Biochemical Basis. Eur. J. Phycol. 2002, 37 (1), 1-17. https://doi.org/10.1017/S0967026201003456.

(58) Reynolds, P. A.; McGillivray, D. J.; Gilbert, E. P.; Holt, S. A.; Henderson, M. J.; White, J. W. Neutron and X-Ray Reflectivity from Polyisobutylene-Based Amphiphiles at the Air-Water Interface. Langmuir 2003, 19 (3), 752-761. https://doi.org/10.1021/la0206920.

(59) Hunter, K. A.; Liss, P. S. Chapter 9 Organic Sea Surface Films. In Elsevier Oceanography Series; Duursma, E. K., Dawson, R., Eds.; Marine Organic Chemistry; Elsevier, 1981; Vol. 31, pp 259-298. https://doi.org/10.1016/S0422-9894(08)70331-3. 
(60) McCluskey, C. S.; Hill, T. C. J.; Malfatti, F.; Sultana, C. M.; Lee, C.; Santander, M. V.; Beall, C. M.; Moore, K. A.; Cornwell, G. C.; Collins, D. B.; Prather, K. A.; Jayarathne, T.; Stone, E. A.; Azam, F.; Kreidenweis, S. M.; DeMott, P. J. A Dynamic Link between Ice Nucleating Particles Released in Nascent Sea Spray Aerosol and Oceanic Biological Activity during Two Mesocosm Experiments. J. Atmos. Sci. 2017, 74 (1), 151-166. https://doi.org/10.1175/JAS-D-16-0087.1.

(61) McCluskey, C. S.; Hill, T. C. J.; Sultana, C. M.; Laskina, O.; Trueblood, J.; Santander, M. V.; Beall, C. M.; Michaud, J. M.; Kreidenweis, S. M.; Prather, K. A.; Grassian, V.; DeMott, P. J. A Mesocosm Double Feature: Insights into the Chemical Makeup of Marine Ice Nucleating Particles. J. Atmos. Sci. 2018, 75 (7), 2405-2423. https://doi.org/10.1175/JAS-D-17-0155.1.

(62) Brown, M. G.; Walker, D. S.; Raymond, E. A.; Richmond, G. L. Vibrational Sum-Frequency Spectroscopy of Alkane/Water Interfaces: Experiment and Theoretical Simulation. J. Phys. Chem. $B$ 2003, 107 (1), 237-244. https://doi.org/10.1021/jp0218589.

(63) Shen, Y. R. 1998 Frank Isakson Prize Address Sum Frequency Generation for Vibrational Spectroscopy: Applications to Water Interfaces and Films of Water and Ice. Solid State Commun. 1998, 108 (7), 399-406. https://doi.org/10.1016/S0038-1098(98)00399-8.

(64) Gragson, D. E.; Richmond, G. L. Investigations of the Structure and Hydrogen Bonding of Water Molecules at Liquid Surfaces by Vibrational Sum Frequency Spectroscopy. J. Phys. Chem. B 1998, 102 (20), 3847-3861. https://doi.org/10.1021/jp9806011.

(65) Gragson, D. E.; Richmond, G. L. Probing the Intermolecular Hydrogen Bonding of Water Molecules at the CCl4/Water Interface in the Presence of Charged Soluble Surfactant. J. Chem. Phys. 1997, 107 (22), 9687-9690. https://doi.org/10.1063/1.475264.

(66) Walker, R. A.; Gruetzmacher, J. A.; Richmond, G. L. Phosphatidylcholine Monolayer Structure at a Liquid-Liquid Interface. J. Am. Chem. Soc. 1998, 120 (28), 6991-7003. https://doi.org/10.1021/ja980736k.

(67) Sovago, M.; Kramer Campen, R.; Bakker, H. J.; Bonn, M. Hydrogen Bonding Strength of Interfacial Water Determined with Surface Sum-Frequency Generation. Chem. Phys. Lett. 2009, 470 (1), 7-12. https://doi.org/10.1016/j.cplett.2009.01.009.

(68) Dalchand, N.; Doğangün, M.; Ohno, P. E.; Ma, E.; Martinson, A. B. F.; Geiger, F. M. Perturbation of Hydrogen-Bonding Networks over Supported Lipid Bilayers by Poly(Allylamine Hydrochloride). J. Phys. Chem. B 2019, 123 (19), 4251-4257. https://doi.org/10.1021/acs.jpcb.9b02392.

(69) Chen, X.; Hua, W.; Huang, Z.; Allen, H. C. Interfacial Water Structure Associated with Phospholipid Membranes Studied by Phase-Sensitive Vibrational Sum Frequency Generation Spectroscopy. J. Am. Chem. Soc. 2010, 132 (32), 11336-11342. https://doi.org/10.1021/ja1048237.

(70) Tang, C. Y.; Huang, Z.; Allen, H. C. Interfacial Water Structure and Effects of $\mathrm{Mg}^{2+}$ and $\mathrm{Ca}^{2+}$ Binding to the $\mathrm{COOH}$ Headgroup of a Palmitic Acid Monolayer Studied by Sum Frequency Spectroscopy. J. Phys. Chem. B 2011, 115 (1), 34-40. https://doi.org/10.1021/jp1062447.

(71) Ma, G.; Chen, X.; Allen, H. C. Dangling OD Confined in a Langmuir Monolayer. J. Am. Chem. Soc. 2007, 129 (45), 14053-14057. https://doi.org/10.1021/ja075806e.

(72) Shen, Y. R.; Ostroverkhov, V. Sum-Frequency Vibrational Spectroscopy on Water Interfaces: Polar Orientation of Water Molecules at Interfaces. Chem. Rev. 2006, 106 (4), 1140-1154. https://doi.org/10.1021/cr040377d.

(73) Griffith, E. C.; Vaida, V. Ionization State of L-Phenylalanine at the Air-Water Interface. J. Am. Chem. Soc. 2013, 135 (2), 710-716. https://doi.org/10.1021/ja308089n.

(74) Griffith, E. C.; Adams, E. M.; Allen, H. C.; Vaida, V. Hydrophobic Collapse of a Stearic Acid Film by Adsorbed L-Phenylalanine at the Air-Water Interface. J. Phys. Chem. B 2012, 116 (27), 7849-7857. https://doi.org/10.1021/jp303913e.

(75) Woden, B.; Skoda, M.; Hagreen, M.; Pfrang, C. Night-Time Oxidation of a Monolayer Model for the Air-Water Interface of Marine Aerosols-A Study by Simultaneous Neutron Reflectometry and in 
Situ Infra-Red Reflection Absorption Spectroscopy (IRRAS). Atmosphere 2018, 9 (12), 471. https://doi.org/10.3390/atmos9120471.

(76) Rudd, B. A. W.; Vidalis, A. S.; Allen, H. C. Thermodynamic versus Non-Equilibrium Stability of Palmitic Acid Monolayers in Calcium-Enriched Sea Spray Aerosol Proxy Systems. Phys. Chem. Chem. Phys. 2018, 20 (24), 16320-16332. https://doi.org/10.1039/C8CP01188E.

(77) Griffith, E. C.; Vaida, V. In Situ Observation of Peptide Bond Formation at the Water-Air Interface. PNAS 2012, 109 (39), 15697-15701. https://doi.org/10.1073/pnas.1210029109.

(78) Mendelsohn, R.; Mao, G.; Flach, C. R. Infrared Reflection-Absorption Spectroscopy: Principles and Applications to Lipid-Protein Interaction in Langmuir Films. BBA - Biomembranes 2010, 1798 (4), 788-800. https://doi.org/10.1016/j.bbamem.2009.11.024.

(79) Mendelsohn, R.; Brauner, J. W.; Gericke, A. External Infrared Reflection Absorption Spectrometry of Monolayer Films at the Air-Water Interface. Annu. Rev. Phys. Chem. 1995, 46 (1), 305-334. https://doi.org/10.1146/annurev.pc.46.100195.001513.

(80) de Brito, A. K.; Caseli, L.; Nordi, C. S. F. Algal Polysaccharides on Lipid Langmuir-Blodgett Films and Molecular Effects upon Metal Ion Contact. Thin Solid Films 2013, 534, 312-315. https://doi.org/10.1016/j.tsf.2013.02.009.

(81) Dousseau, F.; Pezolet, M. Determination of the Secondary Structure Content of Proteins in Aqueous Solutions from Their Amide I and Amide II Infrared Bands. Comparison between Classical and Partial Least-Squares Methods. Biochemistry 1990, 29 (37), 8771-8779. https://doi.org/10.1021/bi00489a038.

(82) Brown, A. G.; Thuman, W. C.; McBain, J. W. The Surface Viscosity of Detergent Solutions as a Factor in Foam Stability. J. Colloid Sci. 1953, 8 (5), 491-507. https://doi.org/10.1016/00958522(53)90055-5.

(83) Brown, A. G.; Thuman, W. C.; McBain, J. W. Transfer of Air through Adsorbed Surface Films as a Factor in Foam Stability. J. Colloid Sci. 1953, 8 (5), 508-519. https://doi.org/10.1016/00958522(53)90056-7.

(84) Falciani, G.; Franklin, R.; Cagna, A.; Sen, I.; Hassanali, A.; Chiavazzo, E. A Multi-Scale Perspective of Gas Transport through Soap-Film Membranes. Mol. Syst. Des. Eng. 2020. https://doi.org/10.1039/C9ME00186G.

(85) Park, E.-Y.; Choi, J. The Performance of Low-Pressure Seawater as a $\mathrm{CO}^{2}$ Solvent in Underwater AirIndependent Propulsion Systems. J. Mar. Sci. Eng. 2020, 8 (1), 22. https://doi.org/10.3390/jmse8010022.

(86) Saltzman, E. S.; King, D. B.; Holmen, K.; Leck, C. Experimental Determination of the Diffusion Coefficient of Dimethylsulfide in Water. J. Geophys. Res. Oceans 1993, 98 (C9), 16481-16486. https://doi.org/10.1029/93JC01858.

(87) Wilke, C. R.; Lee, C. Y. Estimation of Diffusion Coefficients for Gases and Vapors. Ind. Eng. Chem. 1955, 47 (6), 1253-1257. https://doi.org/10.1021/ie50546a056.

(88) Jähne, B.; Heinz, G.; Dietrich, W. Measurement of the Diffusion Coefficients of Sparingly Soluble Gases in Water. J. Geophys. Res. Oceans 1987, 92 (C10), 10767-10776. https://doi.org/10.1029/JC092iC10p10767.

(89) Möller, M. N.; Li, Q.; Chinnaraj, M.; Cheung, H. C.; Lancaster, J. R.; Denicola, A. Solubility and Diffusion of Oxygen in Phospholipid Membranes. BBA - Biomembranes 2016, 1858 (11), 29232930. https://doi.org/10.1016/j.bbamem.2016.09.003.

(90) McCaig, M. S.; Paul, D. R. Effect of Film Thickness on the Changes in Gas Permeability of a Glassy Polyarylate Due to Physical AgingPart I. Experimental Observations. Polymer 2000, 41 (2), 629-637. https://doi.org/10.1016/S0032-3861(99)00172-X.

(91) Tant, M. R.; Wilkes, G. L. An Overview of the Nonequilibrium Behavior of Polymer Glasses. Polym. Eng. Sci. 1981, 21 (14), 874-895. https://doi.org/10.1002/pen.760211403. 
(92) Boyd, P. W.; Doney, S. C.; Strzepek, R.; Dusenberry, J.; Lindsay, K.; Fung, I. Climate-Mediated Changes to Mixed-Layer Properties in the Southern Ocean: Assessing the Phytoplankton Response. Biogeosciences 2008, 5 (3), 847-864.

(93) Elliott, J. A.; Thackeray, S. J.; Huntingford, C.; Jones, R. G. Combining a Regional Climate Model with a Phytoplankton Community Model to Predict Future Changes in Phytoplankton in Lakes. Freshw. Biol. 2005, 50 (8), 1404-1411. https://doi.org/10.1111/j.1365-2427.2005.01409.x.

(94) Bullerjahn, G. S.; McKay, R. M.; Davis, T. W.; Baker, D. B.; Boyer, G. L.; D’Anglada, L. V.; Doucette, G. J.; Ho, J. C.; Irwin, E. G.; Kling, C. L.; Kudela, R. M.; Kurmayer, R.; Michalak, A. M.; Ortiz, J. D.; Otten, T. G.; Paerl, H. W.; Qin, B.; Sohngen, B. L.; Stumpf, R. P.; Visser, P. M.; Wilhelm, S. W. Global Solutions to Regional Problems: Collecting Global Expertise to Address the Problem of Harmful Cyanobacterial Blooms. A Lake Erie Case Study. Harmful Algae 2016, 54, 223-238. https://doi.org/10.1016/j.hal.2016.01.003.

(95) Aller, J. Y.; Radway, J. C.; Kilthau, W. P.; Bothe, D. W.; Wilson, T. W.; Vaillancourt, R. D.; Quinn, P. K.; Coffman, D. J.; Murray, B. J.; Knopf, D. A. Size-Resolved Characterization of the Polysaccharidic and Proteinaceous Components of Sea Spray Aerosol. Atmos. Environ. 2017, 154, 331-347. https://doi.org/10.1016/j.atmosenv.2017.01.053.

(96) Collins, D. B.; Bertram, T. H.; Sultana, C. M.; Lee, C.; Axson, J. L.; Prather, K. A. Phytoplankton Blooms Weakly Influence the Cloud Forming Ability of Sea Spray Aerosol. Geophys. Res. Lett. 2016, 43 (18), 9975-9983. https://doi.org/10.1002/2016GL069922.

(97) DeMott, P. J.; Mason, R. H.; McCluskey, C. S.; Hill, T. C. J.; Perkins, R. J.; Desyaterik, Y.; Bertram, A. K.; Trueblood, J. V.; Grassian, V. H.; Qiu, Y.; Molinero, V.; Tobo, Y.; Sultana, C. M.; Lee, C.; Prather, K. A. Ice Nucleation by Particles Containing Long-Chain Fatty Acids of Relevance to Freezing by Sea Spray Aerosols. Environ. Sci. - Proc. IMP 2018, 20 (11), 1559-1569. https://doi.org/10.1039/C8EM00386F. 
TOC GRAPHIC

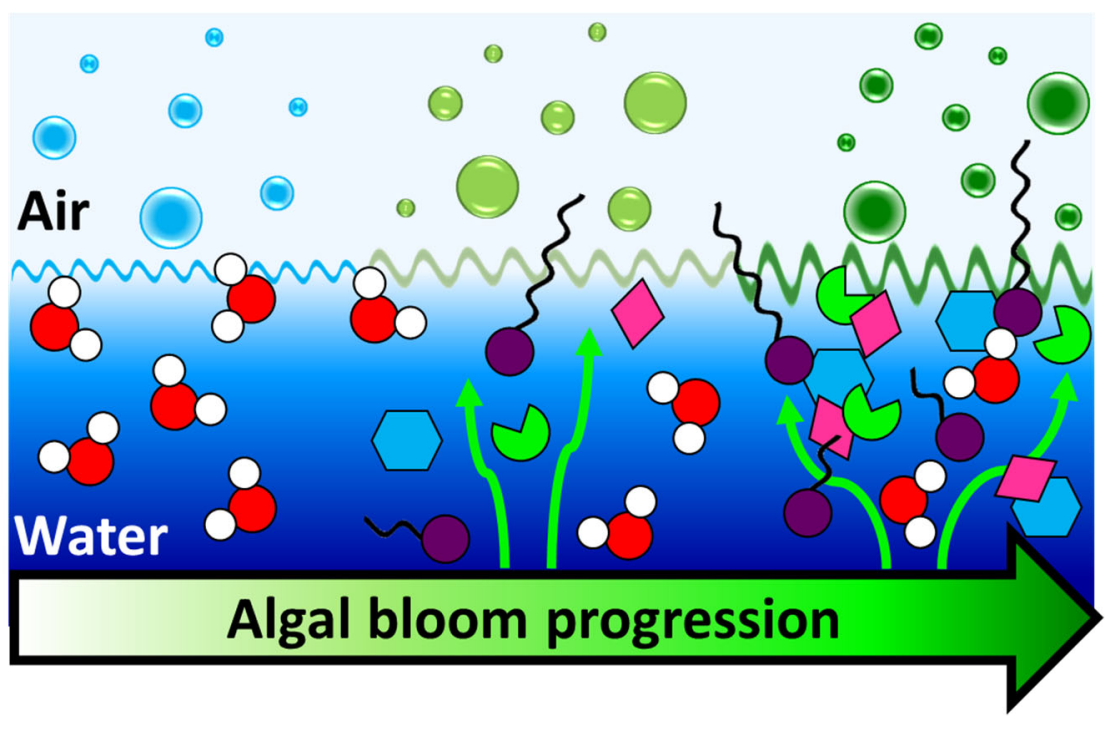

